\title{
Kant's Aesthetic Idealism
}

\section{Guenter Zoeller}

KANT'S Critique of Judgment is a seminal text in philosophical reflection about matters of art and beauty. Yet it is also an exceedingly difficult text for today's reader, due to the fact that it is deeply rooted in the aesthetic discussion of its time, the eighteenth century, and that it forms an integral part of Kant's own comprehensive philosophical system. While it is fairly standard to explain Kant's aesthetics by comparing his views to those of relevant contemporaries and predecessors in the field, little attention has been paid to the structural similarities between Kant's aesthetics and his views on other philosophical matters. In the present piece I want to explore this somewhat neglected line of inquiry. I shall concentrate on Kant's basic account of the conditions and limitations of human knowledge and pursue the extent of analogy between Kant's idealism regarding knowledge and Kant's idealism in aestheticis.

\section{I}

In the Critique of Pure Reason (1781) Kant defends a view which he calls "transcendental idealism." On this view, ordinary empirical objects such as trees and tables have no being independent of the human mind that cognizes them. Kant holds that the human mind plays an active, formative role in experiencing the world. The mind is shown to cognize objects by subjecting what is given through the senses to mental functions. The objects of knowledge that result from those formative processes are said to be indelibly marked by the activities of the human mind. Due to the mind's active, structuring relation to objects, we do not know things as they exist independent and outside of the formation they undergo through the mind. Put in Kant's terminology, we do not know things as they are "in themselves," but only as they "appear to us."

It is important to note that Kant does not deny the reality of things independent of any involvement with the human mind. His point is rather that we cannot know anything about the absolute, mind-independent determinations of those objects. The things in themselves lie outside the sphere of what we humans can possibly experience. Conversely, every- 
thing that we do know on the basis of experience is deeply affected by our human ways of experiencing. Empirical objects "appear" to us under the forms of human cognition. Kant identifies a set of basic mental functions that guide the structuring of our experience. They are space and time as the structuring features of knowledge gained through the senses, and the twelve categories as the structuring features of knowledge gained through the understanding. Most important among the latter is the category of cause and effect, that organizes the rule-governed sequence of events in the realm of experience.

In labeling his position "idealism," Kant indicates the relativity of empirical objects to the human mind and its principal cognitive functions. At points, Kant goes so far as to assert that the whole realm of experience and everything in it has reality only as representations in the human mind, and that it has no reality outside the mind. Kant's idealism, then, amounts to the view that all we can know is mind-dependent in that it is either the mind itself or something that has reality only relative to it. Kant is careful, though, to limit the scope of his idealism. He does not claim that everything is mental; the mind-independent reality of the things in themselves is left untouched. It is only the empirical determinations that are ideal in the sense of having no reality independent of the cognitive processes.

Kant's idealism is furthermore a transcendental idealism, viz., an idealism concerning things in themselves, in that it maintains that the objects we experience do not exist as such outside of their relation to the human mind. Yet Kant is not about to deny all reality to the objects of empirical knowledge. The determinations attributed to objects on the basis of our experience do indeed belong to those objects, provided that the objects are properly understood as being appearances and not things in themselves. In addition to being a transcendental idealist, who denies the absolute reality of empirical determinations, Kant is thus an empirical realist, who holds that the determinations of empirical objects according to space, time and the categories really pertain to those very objects.

On Kant's view, transcendental idealism is not only compatible with empirical realism. To account for the reality of our empirical knowledge outright requires the distinction, made by transcendental idealism, between knowable appearances and unknowable things in themselves. Kant argues that our very ability to have objective knowledge presupposes that the objects to be known lie not outside the sphere of human experi- 
ence but within it, and hence be subject to the human conditions of knowing. If, by contrast, the objects to be known were assumed to be the things as they exist in themselves, independent of human knowledge, then humans would altogether fail in their cognitive efforts. Knowing only appearances is the price to be paid for knowing anything at all.

One of the more elusive features of Kant's transcendental idealism is the claim that the formative processes taking place in cognition are invariant and universal functions of the human mind. While Kant concedes that the acts of cognition take place in individual minds, he nevertheless maintains that the functions underlying these processes are necessarily shared by all human minds. The functions in question are, in Kant's terminology, $a$ priori. Accordingly, the relativity of empirical objects to the human mind is not to be understood as the objects' dependence on some particular mind or on any collection of particular minds. Rather, the relativity is said to pertain with regard to mind "in general." This generic nature of the formative mental functions prevents Kant's idealism from turning into an egoism or solipsism, which maintains that there is only one being, myself. At least, it must be said that the ego or self on which the world of appearances depends is not your or my particular "I" but some unspecific, impersonal super-ego.

Kant's theory of aesthetic judgments, as developed in the Critique of Judgment, suggests a transfer of the idealist conceptuality from the sphere of knowing to that of feeling and of judgment based on feeling. Up through Kant, the term "aesthetic" designates the sphere of what can be known through the senses. Kant's own Transcendental Aesthetic in the Critique of Pure Reason follows this earlier usage by treating of space and time as the sensory conditions of all knowledge. In the third Critique, though, the term "aesthetic" is not referring to sensory cognition and its conditions but to the feeling of pleasure and displeasure. "Aesthetic" no longer designates "what is merely subjective in our presentations of things outside us," and what is "required for cognition of objects outside us," but rather "that subjective feature of a presentation which cannot at all become an element of cognition" (29).

A further terminological peculiarity must be noted. In the Critique of Judgment the term "aesthetic" and its cognates are not limited to consid- 
erations of beauty and fine art. Rather, the aesthetic realm comprises the entire range of feelings or affective attitudes. "Aesthetic" characterizes a basic mode of relating to things, one that is radically different from the cognitive mode. The aesthetic mode is not a particular or strange way of knowing things but a way of relating to things in an entirely different, non-cognitive way-through feeling. In the aesthetic attitude things are not determined as to what they are. Rather, they are determined as to how they make the experiencing subject feel. Yet in spite of its distinctly noncognitive character, the aesthetic mode still finds expression in judgments. In addition to cognitive judgments that specify what is the case, Kant countenances aesthetic judgments that specify the subject's affective stand toward some object.

The major determinations employed in aesthetic judgments include the predicates "agreeable," "beautiful," and "sublime," as well as the corresponding negative determinations - each predicate articulating an affective, emotional stand. These determinations have a peculiar double nature. On the one hand, they are about things: pleasure or displeasure is taken in a particular object or at least in the mental representation of something. On the other hand, the predicates in question are not so much about the object intended as about the experiencing mind itself. In aesthetic judgments we relate to the world through our capacity for feeling pleasure or displeasure. Aesthetic judgments are judgments made through feelings about things to which the mind reacts affectively.

In assessing the idealism involved in Kant's account of aesthetic judgments it must be kept in mind that all aesthetic determinations are built upon some cognitive relation to the world. Experiencing something as agreeable or as determined in any other aesthetically relevant sense requires that the thing in question first enter into the mind's field of awareness. This taking cognizance of the object in question may well be minimal. I do not need to know what exactly the thing I am experiencing is in order to experience it as pleasurable or displeasurable. Yet some act of cognizing the thing in question will always be required before I can react emotionally or affectively to its presence.

On a most basic level, then, aesthetic idealism in Kant is simply a species of the more comprehensive transcendental idealism. The reasoning is straightforward. According to transcendental idealism, everything we experience has being only relative to the human mind. Now among the 
things we experience are objects that are subsequently the target of some affective, aesthetic attitude. Hence, those objects to be apprehended aesthetically have being only relative to the universal human conditions of experience. No matter whether I consider the rose a merely agreeable, a beautiful, or even a disagreeable object, as an object that I can encounter in experience the rose is not a thing in itself but merely an appearance, whose being is relative to human cognitive conditions.

Yet, a case can be made for attributing to Kant a more specific idealism regarding aesthetic matters, a specifically aesthetic idealism. The aesthetic determinations or predicates attributed to such objects as roses are not relative to the human cognitive conditions, but rather to the human conditions regarding the feeling of pleasure and displeasure, which are the basic affective conditions. Aesthetic determinations themselves do not result from acts of taking cognizance of objects, although they may presuppose such acts. Aesthetic predication involves acts of taking pleasure or displeasure in objects. Thus a distinction is introduced between two kinds of predicates attributed to things like roses. On the one hand, there are the cognitive determinations made by the senses and the understanding. For the example of the rose, the cognitive determinations would include the rose's shape and size but also its color, even its scent. On the other hand, there are the aesthetic determinations that articulate the mind's affective reaction to some or all of those perceived cognitive determinations. It is an act of cognition to ascertain that the rose has this particular shade of red. But it is a non-cognitive, an aesthetic matter to undergo a feeling of pleasure or displeasure upon considering the rose's color.

Both sets of determinations just distinguished are predicated of objects only relative to some basic mental capacity. In the case of cognitive predicates, the faculty in question is that of knowing. It is due to the human cognitive constitution that objects of experience appear with the determinations that we attribute to them. Analogously, it is due to the human affective, aesthetic constitution that objects appear to us as pleasurable or displeasurable. The thing in itself that corresponds to the rose is as little pleasure-like as it is red. The thing in question only appears red, due to our human forms of knowing - and it only appears pleasant, due to our human ways of feeling.

So far the emphasis has been on the parallelism between cognitive and aesthetic idealism. There is also, though, a certain disanalogy between the 
two kinds of idealism. The predication of aesthetic determinations, such as "agreeable" or "beautiful," is significantly more subjective than the predication of cognitive properties. In the cognitive attitude the mind focusses on the determinations that belong to the empirical object under consideration. It is an objective fact that a certain object is round, red, and sweet or square, green, and bitter. By contrast, in the aesthetic attitude the mind focusses on its own affective stand toward some object. The aesthetic judgment is primarily about the mind's own affective state. Thus a strong subjective component enters into aesthetic judgments. The affective reaction to the same objective state of affairs, e.g., the redness of the rose, can vary widely from one individual to another. Finding something agreeable is no indication that everyone else will have the same aesthetic response.

Given the basic subjectivity of aesthetic judgments, Kant's aesthetic idealism seems to take on distinctly egoistic and solipsistic overtones. To an aesthetic egoist, finding something pleasurable is not due to some universal human mode of experiencing pleasure but only to specific, even highly individualistic conditions for undergoing states of pleasure. For the vast majority of aesthetic judgments, this is indeed Kant's considered view on the matter. Kant would concede that cultural communalities and other forms of social conditioning bring about a fair amount of agreement among our aesthetic responses. But for the majority of cases, Kant does not acknowledge any principle that would guide the aesthetic judgments of different individuals and would assure their agreement on aesthetic matters.

The two kinds of aesthetic judgments that Kant seeks to exempt from aesthetic egoism are judgments concerning the beautiful and judgments concerning the sublime. The status of the sublime depends on extraaesthetic considerations and can be disregarded in an assessment of Kant's aesthetic idealism. In arguing for the special status of the beautiful Kant employs a distinction between the pleasure we take in sensation and the pleasure we take in perceptual form, especially in spatial configurations. Kant argues that the pleasure taken in perceptual form originates in the mind's focus on that form or shape. The mind's attention to perceptual form becomes aesthetically efficacious when an object's perceptual form is successfully considered with regard to that form's generic suitability for enabling the work of cognition. The object's aesthetically relevant form is its purposiveness, understood as its suitability for engaging the cognitive 
faculties apart from any particular cognitive goal.

According to Kant's psychology of aesthetic experience, the purposive, harmonious engagement of the cognitive faculties gives rise to an experience of pleasure. This pleasure is taken in the object's spatial or temporal form, and the object successfully considered by such aesthetic reflection is termed "beautiful." By contrast, the pleasure taken in mere sensations occurs without any such reflection and therefore does not bring into play any distinctly cognitive processes. The pleasure brought about by sensation is, in Kant's terminology, pleasure taken in the merely "agreeable," and must not be confused with the pleasure taken in the beautiful that arises from the consideration of perceptual form.

Kant's analysis of beauty thus amounts to what could be termed a formal aesthetic idealism, a view that maintains the ideality of the formal purposiveness of certain aesthetic phenomena. The formal purposiveness is not a cognitive determination of the object, one that could be perceived in the way the spatio-temporal form of an object can be perceived. Rather, it is the product resulting from the mind's reflection on the object's perceptual form. The perceptual form has empirical reality. By contrast, the purposive form is ideal or has being only relative to the playful engagement of the cognitive capacities and the resultant affective reaction to it.

By identifying a certain kind of aesthetic experience through its potential for satisfying the most general conditions of knowing, Kant has reintroduced a link between the cognitive and the aesthetic spheres. It must be kept in mind, though, that the aesthetic judgments concerning beauty do not make any specific cognitive claims above their objects. They merely express an object's general suitability to being grasped in the cognitive attitude. One might want to say that the aesthetic attitude provides a playful, disengaged parody of the cognitive process.

The mimicking relation between cognitive and aesthetic judgments just outlined is of the highest strategic importance for Kant's attempt to establish some form of objectivity even in the realm of the aesthetic, that paradigmatic realm of individualistic subjectivity. In exhibiting the psychological conditions appropriate for cognitive judgments, aesthetic judgments about the beautiful partake, at least to some degree, in the objectivity of cognitive judgments. Kant argues that the harmonious relation between the faculties engaged in cognition is the same in all human beings and that an aesthetic judgment based on that harmony could therefore 
claim to express an affective stand which can be shared by everyone else.

Kant has to concede, though, that the analogy between cognitive and aesthetic objectivity is not complete. Unlike cognitive judgments, judgments about beauty do not have an objective, object-based ground that provides a determinate content for the predicate of the judgment in question. Rather, the ground of judgments concerning beauty is conceptually undetermined and based on the subject's feelings. Accordingly, judgments concerning beauty express their claim to everyone's consent not as an argumentatively enforceable claim but as an appeal to an ideal standard. Following eighteenth-century usage, Kant gives this standard the name "taste," and terms judgments concerning beauty "judgments of taste." This, then, would be yet another meaning that the term "aesthetic idealism" assumes in Kant: agreement is an ideal norm, to be pursued for the purpose of regulating aesthetic discourse, with no guarantee to factual agreement - but with good reasons for seeking it by way of sustained aesthetic disagreement. 